\title{
Primary intraosseous squamous cell carcinoma in pre-existing keratocystic odontogenic tumor: A case report and literature review
}

\author{
MING-RU BAI ${ }^{1}$, TING SHEN ${ }^{1,2}$, YU CHEN $^{1,2}$ and NING GENG ${ }^{1,2}$ \\ ${ }^{1}$ State Key Laboratory of Oral Diseases, West China Hospital of Stomatology; ${ }^{2}$ Department of Oral Pathology, \\ West China College of Stomatology, Sichuan University, Chengdu, Sichuan 610041, P.R. China
}

Received May 20, 2015; Accepted October 29, 2015

DOI: $10.3892 / \mathrm{mco} .2015 .678$

\begin{abstract}
Primary intraosseous squamous cell carcinoma (PIOSCC) is a rare type of odontogenic carcinoma that arises within the jaws. PIOSCC has no initial connection with oral mucosa and possibly develops from the residues of the odontogenic epithelium or from an odontogenic cyst or tumor. The diagnosis of PIOSCC can be difficult as it must be differentiated from other odontogenic carcinomas, such as malignant ameloblastoma, from SCCs arising from the overlying oral mucosa, from the primary tumors of the maxillary sinus or nasal mucosa, and from the tumors that have metastasized to the jaws from other primary sites. The present study reported a rare case of a 59-year-old male patient with a course of keratocystic odontogenic tumor for 25 years, between 1988 and 2013, which eventually transformed into PIOSCC after at least five recurrences and corresponding treatments. The mandible excision and titanium plate reconstruction was performed. Follow-up examinations have revealed no sign of recurrence thus far. The present study discussed this case from three aspects of clinical history, radiological examination and pathological features.
\end{abstract}

\section{Introduction}

Primary intraosseous squamous cell carcinoma (PIOSCC) is a rare form of odontogenic carcinoma arising within the jaw. PIOSCC has no initial connection with the oral mucosa and possibly develops from residual odontogenic epithelium or an

Correspondence to: Dr Ning Geng, Department of Oral Pathology, West China Hospital of Stomatology, Sichuan University, No. 14, Section 3, Renmin South Road, Chengdu, Sichuan 610041, P.R. China

E-mail: gengning@scu.edu.cn

Abbreviations: PIOSCC, primary intraosseous squamous cell carcinoma; PIOC, primary intraosseous carcinoma; KCOT, keratocystic odontogenic tumor; OKC, odontogenic keratocyst

Key words: primary intraosseous carcinoma, mandible, recurrence, inflammation, keratocystic odontogenic tumor odontogenic cyst or tumor (1). Diagnosis of PIOSCC can be difficult as it must be differentiated from other odontogenic carcinomas, including malignant ameloblastoma, SCC arising from the overlying oral mucosa, primary tumors of the maxillary sinus or nasal mucosa, and metastatic tumors from other primary sites (2-4).

The present study reported the case of a 59-year-old male patient who was initially diagnosed with a cystic mandibular lesion in 1988, which was definitively diagnosed as a keratocystic odontogenic tumor (KCOT) in 2006. From 1988 to 2013, the patient experienced at least five recurrences and corresponding treatments. Eventually, the lesion underwent malignant transformation to form a well-differentiated squamous cell carcinoma in the mandible.

\section{Case report}

Clinical history. A 59-year-old male was referred to the Department of Oral and Maxillofacial Surgery (West China Hospital of Stomatology, Sichuan University, Sichuan, China), with a long medical history of repeated treatments and recurrences of a mandibular cystic lesion, as summarized in Table I.

The patient received an initial treatment of cyst curettage for a cystic lesion of the mandible in 1988 at a local hospital. However, the patient could not provide further details regarding this diagnosis and treatment. In 2006, the patient underwent a thorough examination in the West China Hospital of Stomatology, followed by an additional cyst curettage and a definitive diagnosis of mandibular KCOT. However, a recurrence occurred again in 2013. The patient complained of progression in the left mandible and mental region with facial asymmetry over 5 months. The main body of the mandible appeared to be expanding and was clearly irregular upon palpation. The bone wall was extremely thin and flexible. No significantly enlarged submandibular or cervical lymph nodes were palpated.

Mandibular excision and titanium plate reconstruction was performed in September 2013. Postoperative pathology revealed malignant transformation arising from KCOT. Follow-up examinations revealed no sign of recurrence thus far.

Radiological examination. Separate panoramic image examinations performed in 2009 and 2011 revealed a multilocular 
Table I. Clinical history of the patient.

\begin{tabular}{|c|c|c|c|}
\hline Timeline & Lesion site and size & Treatment & Diagnosis \\
\hline 1988 & Left mandible, size N/A & Cyst curettage & Cystic lesion $^{\mathrm{a}}$ \\
\hline 1990 & Left mandible, size N/A & Cyst curettage & Cystic lesion ${ }^{\mathrm{a}}$ \\
\hline \multirow[t]{2}{*}{ October 2006} & Left mandible, $5 \times 4 \mathrm{~cm}$ swelling & & \\
\hline & Right mandible, $3 \times 3 \mathrm{~cm}$ swelling & Cyst curettage & KCOT in mandible \\
\hline September 2007 & $\begin{array}{l}\text { Mentum and left mandible, } \\
3 \times 3 \mathrm{~cm} \text { swelling }\end{array}$ & Cyst curettage & KCOT in mandible \\
\hline October 2009 & $\begin{array}{l}\text { Mentum, } 2.0 \times 2.0 \times 1.8 \mathrm{~cm} \\
\text { swelling }\end{array}$ & Cyst curettage & $\begin{array}{l}\text { KCOT in mandible with } \\
\text { local infection }\end{array}$ \\
\hline December 2009 & Mentum, $3 \times 2 \mathrm{~cm}$ swelling & $\begin{array}{l}\text { Windowing in sulcus } \\
\text { vestibular and drainage }\end{array}$ & No pathological diagnosis \\
\hline January 2011 & $\begin{array}{l}\text { Mentum and left mandible, } \\
2 \times 2 \mathrm{~cm} \text { swelling }\end{array}$ & Windowing in lesion area & $\begin{array}{l}\text { Inflammatory granulation and } \\
\text { necrotic tissue }\end{array}$ \\
\hline October 2013 & $\begin{array}{l}\text { Mentum and left mandible, } \\
5 \times 5 \mathrm{~cm} \text { swelling }\end{array}$ & $\begin{array}{l}\text { Whole mandible resection } \\
\text { and reconstruction }\end{array}$ & $\begin{array}{l}\text { Squamous cell carcinoma } \\
\text { arising in KCOT in mandible }\end{array}$ \\
\hline
\end{tabular}

aPatient provided this information without medical record.

cystic lesion within the main body and bilateral ramus in the mandible (Fig. 1A and B). This lesion appeared as a low-density area with honeycomb and clear trabecular structures, extending along the long axis of the mandible within clear boundaries. Cortical regions of the inferior mandible were destroyed. Roots of the teeth involved did not show any evident absorption. A further panoramic radiograph performed in 2013 showed bilateral destruction of the molars and an enlarged chin with sharp borders (Fig. 1C). No tooth root resorption or periosteal reaction was observed.

Radiographical examination of the chest revealed no evidence of distant metastasis or nevoid basal cell carcinoma syndrome.

Pathological features. The initial diagnosis of a cystic mandibular lesion reported was based on the description of the patient without additional proof from medical records.

The patient first presented to the West China Hospital of Stomatology in 2006. Pathological diagnosis of the lesion was KCOT with typical histological features, including cystic structure, thin epithelium of 5-10 cell layers, stratified squamous epithelium with parakeratosis, basal cells with palisade arrangement and inverted polarity, and a thick fibrous capsule. No daughter cysts or atypical changes were observed.

Pathological diagnoses of inflammatory granulation and inflammatory granulation with local KCOT recurrence were made in 2007 and 2009, respectively. No malignant transformation was apparent at these times.

A pathological diagnosis of primary intraosseous squamous cell carcinoma of the mandible with pre-existing KCOT was made in 2013. The affected tissue and bone measured $14 \times 5 \times 4 \mathrm{~cm}$. The body and both rami of the mandible were expanded, with local bone destruction. The cutting surface of the neoplasm exhibited a honeycomb structure with hemorrhage and necrosis present. Microscopic examination revealed features that were typical of KCOT and highly differentiated squamous cell carcinoma (Fig. 2A-D). Tumor cells had also infiltrated the surrounding bone (Fig. 2B and C). Areas of transition from the benign lining epithelium to dysplastic epithelium to malignant cells were easily identified (Fig. 2E). The epithelium surrounding cancerous cells appeared hyperplastic, with increased cellular pleomorphism and karyokinesis (Fig. 2E and F). Basal cells retained a palisade arrangement and inverted polarity, even in areas of dysplastic and malignant appearance (Fig. 2F). Well-differentiated squamous cell carcinoma was present within the KCOT lesion, revealing a transition from an apparently normal cyst lining to invasive squamous cell carcinoma.

\section{Discussion}

PIOSCC is an uncommon neoplasm of the mandible, which was first described by Loos in 1913 (5). The term primary intraosseous carcinoma (PIOC) was previously used to describe this type of lesion as per the earlier editions of the World Health Organization (WHO) classification for histological typing of odontogenic tumors. However, the new WHO classification (2005) replaces PIOC with PIOSCC, and details three subtypes of lesion: Solid, KOTC-derived and odontogenic cyst-derived (1).

The main obstacle limiting a thorough understanding of the clinical, pathological and bio-behavioral profiles of PIOSCC is the rarity of the condition. However, common criteria for PIOSCC have been established based on published case reports as follows: i) The absence of another primary tumor on chest radiographs to exclude metastasis; ii) the absence of an ulcer in the oral mucosa overlaying the tumor; and iii) histopathological evidence of transition of the epithelial lining into squamous cell carcinoma $(2-4,6,7)$.

Determining the incidence of PIOSCC derived from odontogenic lesions is difficult. When the disease is not observed at an early stage, it is difficult to demonstrate the actual site of malignant transformation as the carcinoma may destroy the structures of the original lesion. For the current patient, 

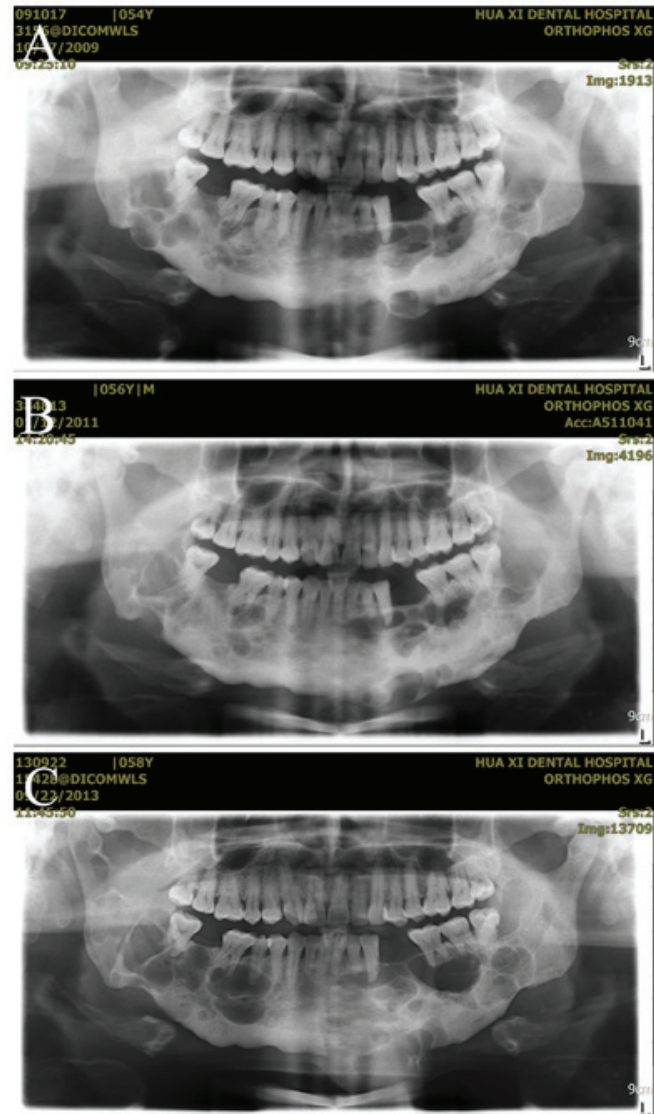

Figure 1. Panoramic image examinations performed in 2009, 2011 and 2013 (A and B) Panoramic image examinations performed in 2009 and 2011 revealing a multilocular cystic lesion within the main body and bilateral ramus in the mandible. This lesion appeared as a low-density area with honeycomb and clear trabecular structures, extending along the long axis of the mandible within clear boundaries. Cortical regions of the inferior mandible were destroyed. Roots of the teeth involved did not show any evident absorption. (C) A further panoramic radiograph performed in 2013 showed bilatera destruction of the molars and an enlarged chin with sharp borders. No tooth root resorption or periosteal reaction was observed.

medical records were available prior to malignant transformation. Furthermore, a typical KCOT structure was still apparent in tissue sections acquired in 2013. Therefore, a diagnosis of PIOSCC subsequent to KCOT was not difficult to establish.

The pathogenesis of PIOSCC remains unclear. For the present case, we speculated that a key factor for malignant transformation was chronic inflammation from the infection of odontogenic lesions. The patient suffered long-term chronic inflammatory stimulation following surgical treatments. Tissue sections supported this theory, with lymphocytic and neutrophilic infiltration of the stroma evident. Previous incision and drainage of the lesion might have led to this inflammatory cell infiltration. Such an inflammatory microenvironment, as is present in the epithelium lining KCOT lesions, confers a high risk for carcinogenesis, as recently described by Sukegawa et al (8).

The WHO classification of odontogenic cysts and tumor (2005) designates an odontogenic keratocyst (OKC) as a KCOT due to the tumor-like character and aggressive biological behavior, although certain disputes continue regarding OKC classification. Regardless of whether KCOTs are cystic lesions or tumors, their biological behavior is clear. Certain
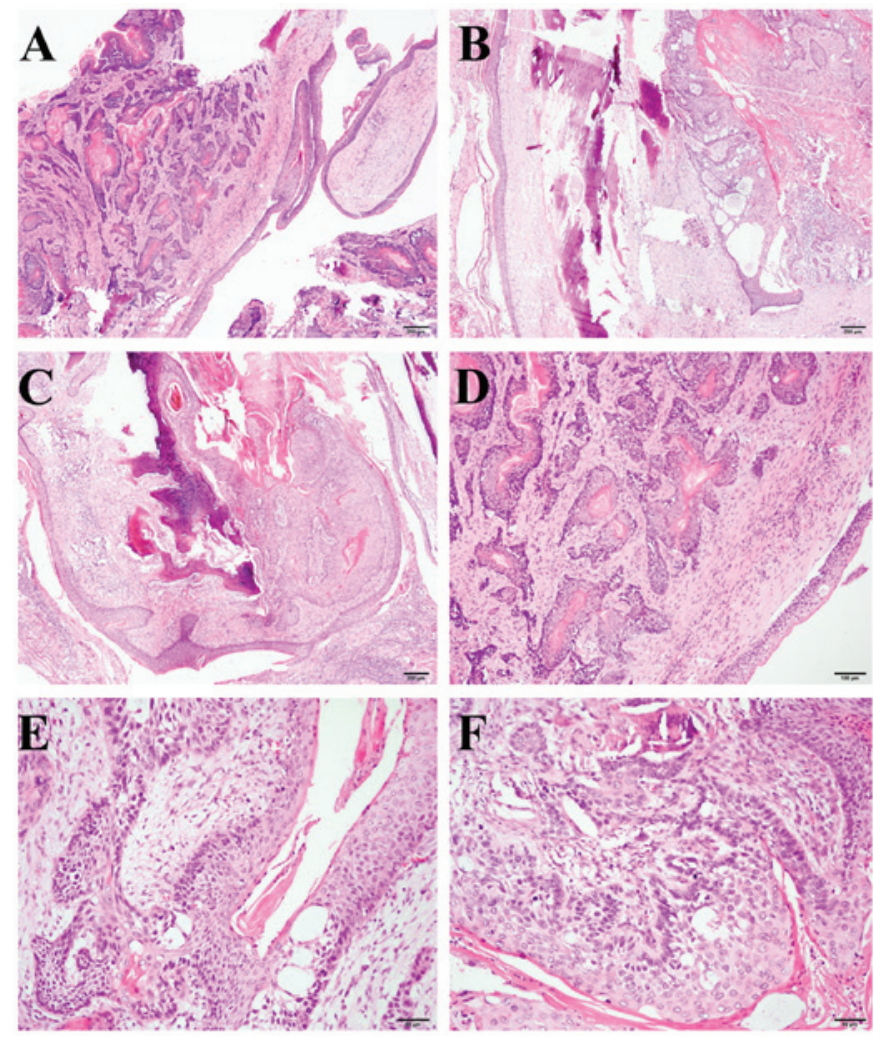

Figure 2. Microscopic examination revealing primary intraosseous squamous cell carcinoma. (A-D) Microscopic examination revealed features typical of keratocystic odontogenic tumor and highly differentiated squamous cell carcinoma. (B and C) Tumor cells had also infiltrated surrounding bone. (E) Areas of transition from benign lining epithelium to dysplastic epithelium to malignant cells were easily identifiable. (E and F) Epithelium surrounding cancerous cells appeared hyperplastic, with increased cellular pleomorphism and karyokinesis. (F) Basal cells retained a palisade arrangement and inverted polarity even in areas of dysplastic and malignant appearance.

KCOT linings exhibit characteristics of epithelial dysplasia, and can develop into squamous cell carcinoma. However, not all studies of $\mathrm{OKC} / \mathrm{KCOT}$ contain information regarding malignant potential. Perhaps of more importance to KCOT management than malignant transformation is the tendency of these lesions to recur. The recurrence rate for KCOT ranges from 0 to $62 \%$, with lesions typically reappearing within 5-7 years $(1,9)$.

KCOT is conventionally treated using curettage or enucleation. However, the high number of recurrences and subsequent repeated treatments may have promoted malignant transformation in the present patient. This suggests that regional osteotomy should be carried out following several recurrences of KCOT to reduce the risk of malignant transformation. Furthermore, avoidance of secondary infection of the lesion may also reduce the risk of malignancy by limiting inflammation in the region.

The treatment of patients with carcinomas arising in cysts has varied from local block excision to radical resection, with or without radiation or adjunctive chemotherapy. According to previous studies, the prognosis is quite poor, with 5-year survival rates ranging from 30 to $40 \%$ (3). However, metastases to regional lymph nodes have been demonstrated in only a limited number of cases. 
The current study presents a case of PIOSCC developing from pre-existing KOCT based upon medical history, clinical examination and histopathological findings. Long-term chronic inflammation and multiple recurrences may aggravate the risk for malignant transformation of KCOT lesions.

\section{References}

1. Bodner L, Manor E, Shear M and van der Waal I: Primary intraosseous cell carcinoma arising in an odontogenic cyst: $\mathrm{A}$ clinicopathologic analysis of 116 reported cases. J Oral Pathol Med 40: 733-738, 2011.

2. Suei Y, Tanimoto K, Taguchi A and Wada T: Primary intraosseous carcinoma: Review of the literature and diagnostic criteria. J Oral Maxillofac Surg 52: 580-583, 1994.

3. Thomas G, Pandey M, Mathew A, Abraham EK, Francis A, Somanathan T, Iype M, Sebastian P and Nair MK: Primary intraosseous carcinoma of the jaw: Pooled analysis of world literature and report of two new cases. Int J Oral Maxillofac Surg 30: 349-355, 2001.

4. Huang JW, Luo HY and Li TJ: Primary intraosseous squamous cell carcinoma of the jaws: Clinicopathologic presentation and prognostic factors. Arch Pathol Lab Med 133: 1834-1840, 2009.

5. Loos D: Central epidermoid carcinoma of the jaw. Dtsch Monatschr Zahnheik 31: 308, 1913.
6. Lugakingira M, Pytynia K, Kolokythas A and Miloro M: Primary intraosseous carcinoma of the mandible: Case report and review of the literature. J Oral Maxillofac Surg 68: 2623-2629, 2010

7. Choi YJ, Oh SH, Kang JH, Choi HY, Kim GT, Yu JJ, Choi YS and Hwang EH: Primary intraosseous squamous cell carcinoma mimicking periapical disease: A case report. Imaging Sci Dent 42: 265-270, 2012.

8. Sukegawa S, Matsuzaki H, Katase N, Kanno T, Mandai T, Takahashi Y, Asaumi JI and Furuki Y: Primary intraosseous squamous cell carcinoma of the maxilla possibly arising from an infected residual cyst: A case report. Oncol Lett 9: 131-135, 2015.

9. González-Alva P, Tanaka A, Oku Y, Yoshizawa D, Itoh S, Sakashita H, Ide F, Tajima Y and Kusama K: Keratocystic odontogenic tumor: A retrospective study of 183 cases. J Oral Sci 50: 205-212, 2008 